\title{
From the Collisionally Induced Dissociation to the Enzyme-Mediated Reactions: The Electron Flux Within the Lignan Furanic Ring
}

\author{
Andreina Ricci and Simona Piccolella \\ Second University of Naples \\ Italy
}

\section{Introduction}

The coupling of high-performance liquid chromatography (HPLC) with tandem mass spectrometry (MS/MS) is nowadays routinely used for the quali- and quantitative analysis of complex organic mixtures such as plant extracts, biological fluids, foods, etc. In this context the MS/MS detector, through the MRM or SMR techniques, ensures an excellent selectivity and sensitivity of basic importance in quantitative trace analysis. However, a reliable quantitative analysis assumes the knowledge of the analyte mass fragmentation pattern and of its energy resolved CAD mass spectra, allowing the accurate and effective choice of both the $\mathrm{m} / \mathrm{z}$ ratio fragments and collision energies for the monitored transitions. Literature on mass spectrometric data concerning the fragmentation pattern of many plant secondary metabolites is almost limited to few classes of compounds. This issue represents the main object of our experimental research (Ricci et al, 2008; Ricci et al, 2010; Ricci et al, 2010).

In this chapter first we will focus on the structural investigation studies by tandem mass spectrometry of plant secondary metabolites belonging to the two classes of furofuranic lignans (FUR) and tetrahydrofuranic lignans (THF).

Further topics discussed will include gas phase ion molecules evidences emerging from MS/MS studies and their contribution to the comprehension of enzyme mediated reactions. In fact, gas phase ion chemistry studies, performed by investigating the mechanisms of predominant Collisionally Activated Dissociations by Mass Spectrometry (CAD/MS), can offer the possibility to investigate the "intrinsic" electronic properties of organic molecules. The isomerization/fragmentation processes induced in the MS/MS experiments can be influenced by a number of environmental factors, and their effect on the stability/reactivity of analytes can be extrapolated to different solvent-free environments. It is known that the effectiveness of enzyme mediated reactions depends dramatically on the high specificity of steric and electronic interactions between the substrate and the biological molecule. In this context, the "intrinsic reactivity" of the substrate plays a fundamental role and its study represents an essential tool for understanding the mechanism of enzymatic processes and for addressing theoretical effort toward the comprehension of the most important interactions leading to the enzymatic reactions. 


\section{Furofuranic and tetrahydrofuranic lignans and their glycosides}

\subsection{The importance of lignans}

Lignans are a widespread group of important plant secondary metabolites, sharing a structure in which two cinnamic acid residues or their biogenetic equivalents are joined. The most abundant type of lignans found in nature consists of two phenylpropanoid units, linked by a carbon-carbon bond between the carbon chains (positions 8 and $8^{\prime}$ ). Lignans are found in roots, stems, leaves, seeds and fruits of vascular plants and are related to lignin. Despite their not complex chemical structure, the several hundreds of lignans up to now identified belong to different classes of chemical compounds, such as furofurans, tetrahydrofurans, dibenzylbutanes, dibenzylbutyrolactones, aryltetrahydronaphthalenes, arylnaphthalenes and dibenzocyclooctadienes. It depends on the way the oxygen atom is incorporated into the molecule and on the kind of cyclization. They occur either in free form or glycosidically linked to different carbohydrates.

In particular the skeleton of furofuranic lignans, depicted in figure 1, shows two tetrahydrofuranic rings connected to two aromatic rings which can have one or more substituents at the 3,4, 3', 4' positions. Tetrahydrofuranic lignans have only one tetrahydrofuranic ring which is bound to a phenyl and benzyl ring at the 7 and $8^{\prime}$ positions, respectively (figure 1).
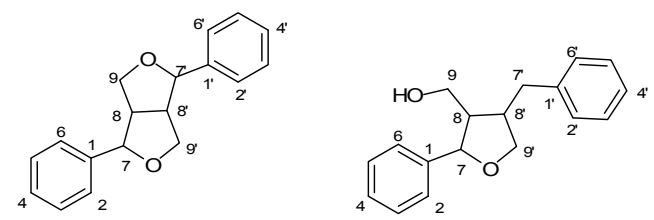

Fig. 1. Chemical skeleton of investigated FUR and THF lignans.

Lignans possess significant pharmacological activities, such as, e.g. for tetrahydrofuranic lignans, anti-parasite, antibacterial, antifungal, anti-tumoral, anti-inflammatory and plateletactivating factor (PAF) inhibition.

Some plant lignans can be converted by intestinal bacteria into the so-called enterolignans, enterodiol and enterolactone. Secolariciresinol and matairesinol are known to undergo this metabolism, but recently the number of lignans probed to be the enterolignans precursors has been enlarged, including also pinoresinol, lariciresinol and sesamin.

\subsection{Tandem mass spectrometry in the structural characterization of furanic lignans}

Due to their possible role in human health, the isolation and identification of new bioactive lignans from complex matrices is an important analytical issue. The coupling of highperformance liquid chromatography (HPLC) with mass spectrometry (MS) is routinely used for the characterization of lignans and their glycosides in organic mixtures. In spite of the importance of lignans, systematic ESI tandem mass spectrometric investigations on these compounds are yet limited to specific lignan sub-classes and rather incomplete (Eklud et al, 2008). However this technique can make efficient, straightforward and unambiguous their identification in plant extracts. Systematic tandem mass spectrometric studies on different types of lignans and their glycosides have been only recently reported. Most of the mass spectrometric data concerns the fragmentation patterns of their $[\mathrm{M}-\mathrm{H}]$ - ions. 
In figure 2 the chemical structures of FUR and THF lignans investigated by tandem mass spectrometry in our laboratory are presented.

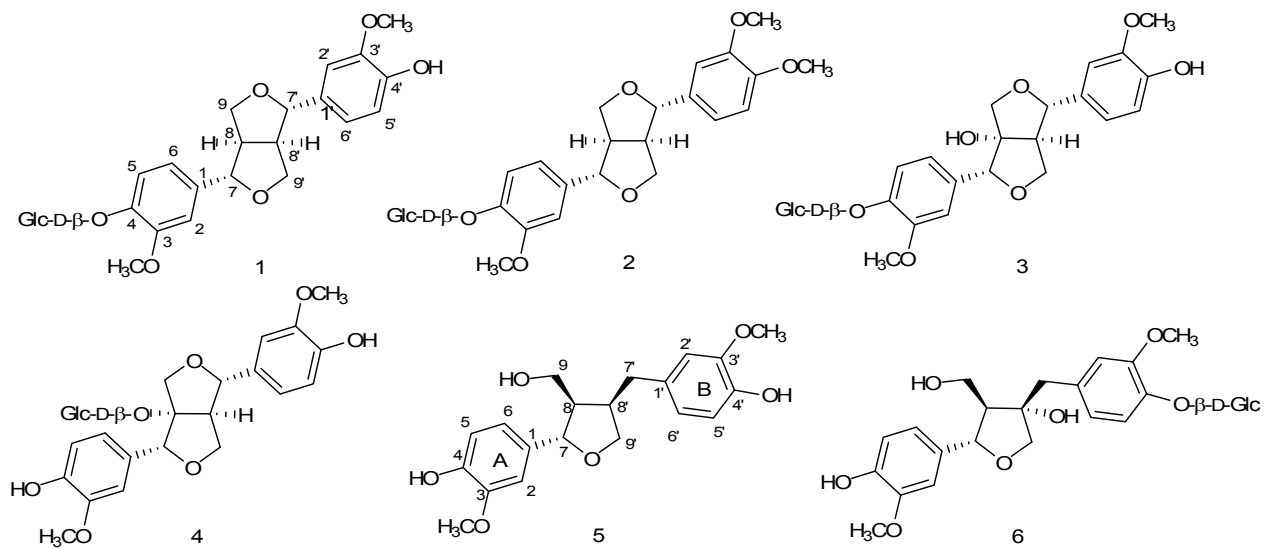<smiles>COc1cc(O)cc(C[C@]2(O)CO[C@@H](c3ccc(OC(=O)OCc4ccccc4)c(OC)c3)[C@H]2CO)c1</smiles><smiles>COc1cc(C[C@@H]2CO[C@@H](c3ccc(O)c(OC)c3)[C@H]2CO)ccc1O</smiles><smiles>COc1cc(C[C@@H](CO)[C@H](CO)Cc2ccc(O)c(OC)c2)ccc1O</smiles>

Fig. 2. Chemical structures of investigated FUR and THF lignans.

\subsubsection{Positive ion mode}

Useful information were obtained in the positive ion mode and CAD/MS spectra of $[\mathrm{M}+\mathrm{H}]^{+}$ ions and of alkali metal cation adducts were proposed for their rapid and unambiguous identification in plant extracts (Ricci et al, 2008; Ricci et al, 2010).

The CAD mass spectra of glycosylated lignans coordinated to different alkali metal cations $\left(\mathrm{Alk}^{+}\right.$, e.g. $\mathrm{Li}^{+}, \mathrm{Na}^{+}, \mathrm{K}^{+}, \mathrm{Rb}^{+}, \mathrm{Cs}^{+}$) showed that when $\mathrm{Alk}^{+}=\mathrm{Cs}^{+}, \mathrm{Rb}^{+}, \mathrm{K}^{+}$the adducts dissociated into the $\mathrm{Alk}^{+}$cation and the lignan glycoside, thus no providing structural information. However, the $[\mathrm{M}+\mathrm{Li}]^{+}$and $[\mathrm{M}+\mathrm{Na}]^{+} \mathrm{CAD}$ mass spectra revealed the presence of structurally diagnostic product ions.

All the $[\mathrm{M}+\mathrm{Na}]^{+} \mathrm{CAD}$ mass spectra of the investigated glycosylated lignans showed ions arising from the loss of the hexose residue as -162 Da when the sugar is bound to a phenolic oxygen (figure 3a), and as $-180 \mathrm{Da}$ when glycosylation occurs at an alcoholic $\mathrm{OH}$ group (figure 3b). 

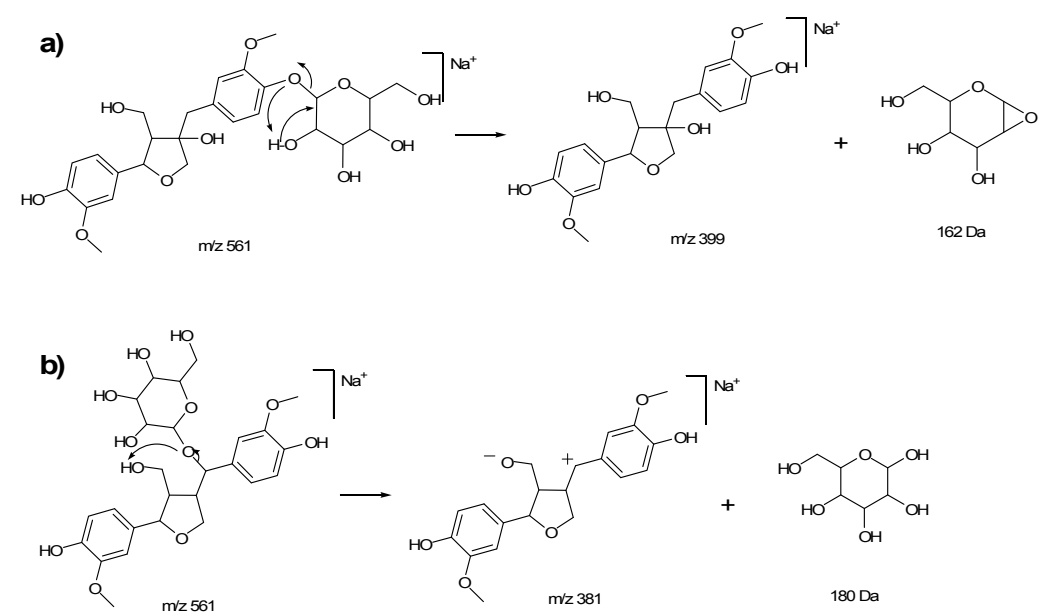

Fig. 3. Hypothesized mechanism for the loss of the hexose as (a) -162 Da, and (b) -180 Da.

If the $\mathrm{Na}^{+}$cation is retained by the sugar moiety the ion at $m / z 185(162+23)$, corresponding to the sodiated hexose moiety, is present in the spectrum (figure 4 ).

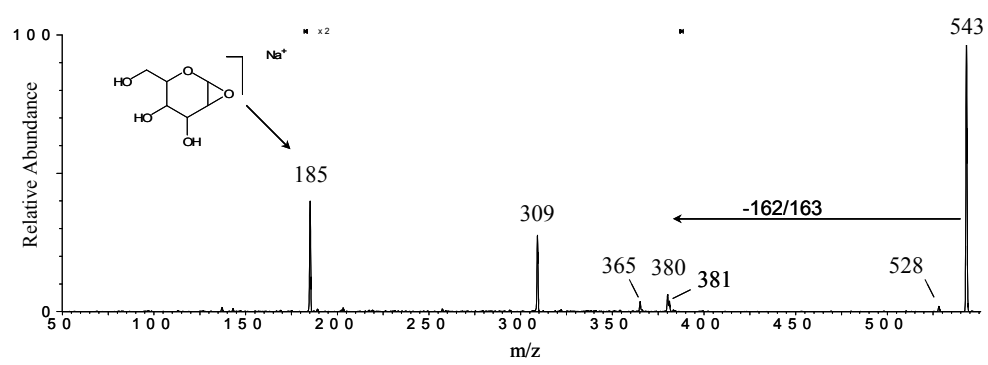

Fig. 4. $[\mathrm{M}+\mathrm{Na}]^{+} \mathrm{CAD}$ mass spectrum of pinoresinol (compound $\mathbf{1}$ ).

In addition, for the sodiated adduct of pinoresinol (compound 1), homolytic cleavage of the glycosidic bond, leading to the elimination of a radical glucosyl moiety (163 Da) and generating the sodiated radical aglycone ion, was also observed (figure 4). The nature and the intensities of the fragments observed in the [M+Alk]+ CAD mass spectra of FUR and THF lignan glucosides reasonably reflects the gas-phase strength of the multisite coordinative bond between the alkali metal cations and the cation-coordinating groups of lignan glycosides. For example if the intensities of the sodiated aglycone ion, arising from a neutral loss of $162 \mathrm{Da}$, and of the sodiated sugar fragment at $\mathrm{m} / z 185$ are comparable, the strength of the interaction between the alkali metal cation with the coordinating group and the sugar residue could be comparable.

To obtain information on the nature of product ions generated during TQ/CAD processes, thus confirming our fragmentation mechanism hypotheses, the H/D solution exchange proved to be a very effective tool. In these experiments lignan glucosides were dissolved in a $\mathrm{D}_{2} \mathrm{O} / \mathrm{CD}_{3} \mathrm{OD}$ solution and all the acidic $\mathrm{H}$ atoms, namely those bonded to the oxygen atoms, undergo selectively D exchange. For this reason the $\mathrm{m} / \mathrm{z}$ ratio of precursor and fragment ions 
increases according to the number of incorporated D atoms. Therefore, when the glucose is present in the molecule, four $\mathrm{D}$ atoms belong to the sugar moiety, and if it is bound to a phenolic $\mathrm{OH}$ group the loss of $165 \mathrm{Da}$ (instead of 162) occurs. The fourth deuterium is transferred to the aglycone in accordance with the mechanism described in figure 3a.

$\mathrm{H} / \mathrm{D}$ exchange experiments played a key role in explaining a different dissociation mechanism observed for lignan 6 . In the CAD mass spectrum of the sodiated adduct of this compound (at $m / z$ 561) a fragment ion (at $m / z$ 381), derived from the neutral loss of $180 \mathrm{Da}$, was detected, but in this case it was found to not correspond to the sugar moiety owing to the lower number of deuterium atoms incorporated in the fragment. The hypothesized mechanism is proposed in figure 5 .

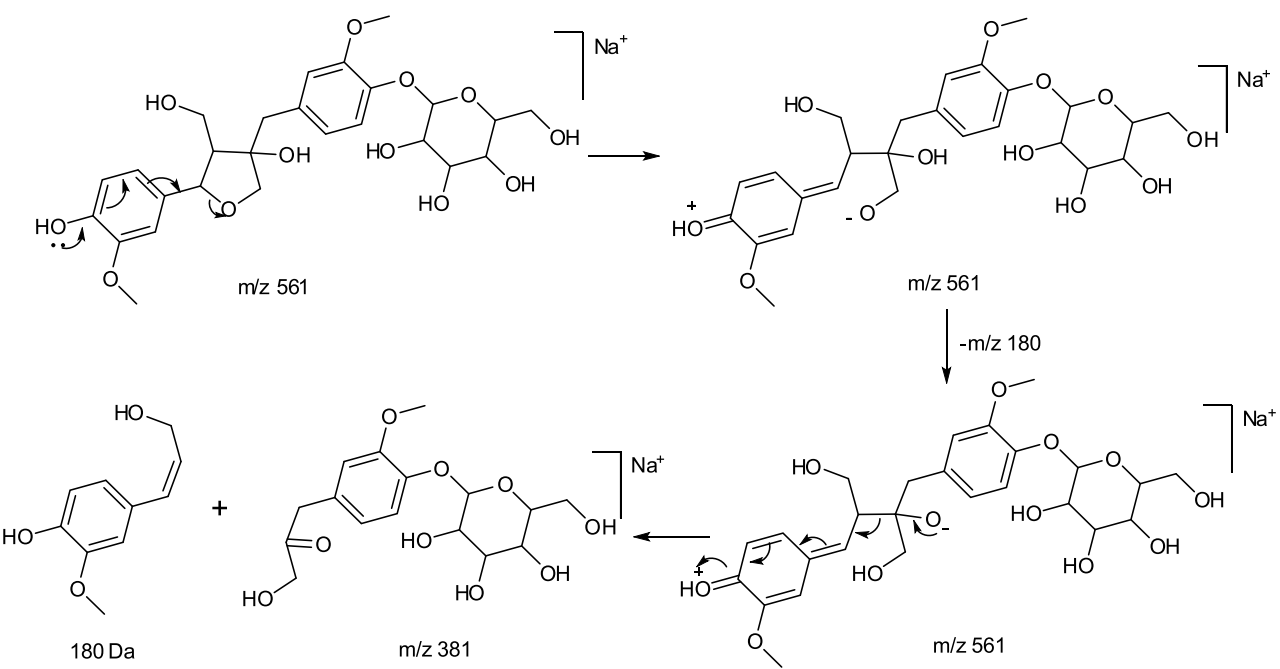

Fig. 5. Proposed mechanism for the loss of a 180 Da moiety not containing the hexose residue.

Moreover, in the positive ion mode, the mass spectra of sodiated adducts of compounds 1-3 and 8, that is of FUR and THF lignan glucosides bonding the sugar at the oxygen in the C-4 position of the guaiacyl moiety, showed a structurally diagnostic ion at $\mathrm{m} / \mathrm{z} 309$, never described before and arising from the loss of the $\left[\mathrm{CH}_{3} \mathrm{O}-\mathrm{C}_{6} \mathrm{H}_{4}-\mathrm{O}\right.$-glucosyl] moiety, namely the glucosilated guaiacyl group, coordinated to the $\mathrm{Na}^{+}$ion. The nature of this fragment was hypothesized on the basis of the following evidences:

1. this ion was not detected in the $[\mathrm{M}+\mathrm{Na}]^{+} \mathrm{CAD}$ mass spectra of lignans which bound the glucose moiety in a position different from C-4;

2. the ion shifted from $\mathrm{m} / z 309$ to 293 when $\mathrm{Li}^{+}$instead of $\mathrm{Na}^{+}$was used as chelating ion;

3. after $\mathrm{H} / \mathrm{D}$ solution exchange in the $[\mathrm{M}+\mathrm{Na}]^{+} \mathrm{CAD}$ spectra of deuterated lignans $1-3$ and 8 , the ion at $\mathrm{m} / \mathrm{z} 309$ shifted to 313 according to the presence of four deuterium atoms.

In this case, our mechanistic hypothesis involves that the $\mathrm{Alk}^{+}$cation interacts mainly with the glycosidic bridging oxygen, as depicted in figure 6 . This hampers the proton transfer from the sugar to the aglycone because the $\mathrm{Na}^{+}$chelation decreases the basicity of the bridging glycosidic oxygen atom, preventing the glycosidic bond cleavage. 


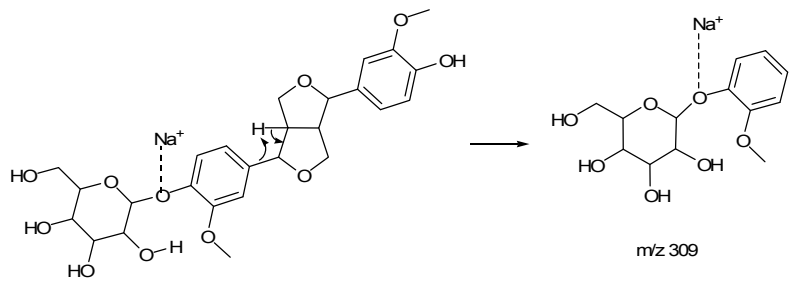

Fig. 6. Proposed mechanism for the formation of the fragment ion at $m / z 309$.

\subsubsection{Negative ion mode}

In the negative ion mode CAD mass spectra of deprotonated glycosylated lignans showed the typical neutral loss of the glucose moiety as 162 or $180 \mathrm{Da}$ through the same mechanisms described above in the positive ion mode. Furthermore, if deprotonation occurs at the sugar residue, the ion at $\mathrm{m} / \mathrm{z} 161$ is present in the spectrum (figure 7).

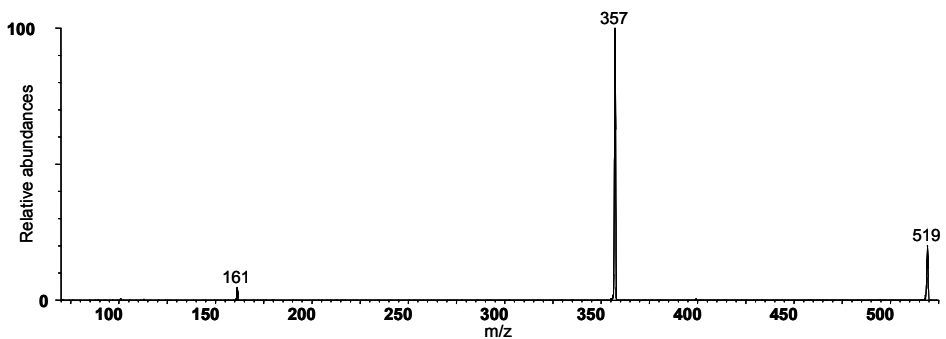

Fig. 7. CAD mass spectrum of deprotonated pinoresinol (lignan 1) at $m / z 519$.

In the negative ion mode our attention has been mainly devoted to the fragmentation of the lignan aglycone ions arising from the in-source CAD of glucosylated species in order to study their most significant fragmentation patterns. For this purpose we recorded energy resolved TQ/CAD mass spectra of deprotonated aglycone lignans (1-4 and 6-8) that were used in a qualitative way to infer information on the integrated energetic picture of main $\mathrm{CAD}$ fragmentations and to investigate the mechanism of the predominant dissociation/isomerisation processes. On the basis of the hypothesized fragmentation mechanisms, gas-phase features of the furanic ring were derived. As an example in figure 8 the energy resolved CAD mass spectra of deprotonated pinoresinol glucoside and of its aglycone, generated by in-source $\mathrm{CAD}$, are reported.

In the case of pinoresinol the symmetry of the molecule makes the nature of fragmentation products independent from the negative charge localization. According to the mechanism depicted in figure 8 , the formation of the ion at $m / z 151$, the main fragmentation pathway of pinoresinol, arose from the cleavage of the $\mathrm{C}^{\prime}-\mathrm{C}^{\prime}$ (or $\mathrm{C} 7-\mathrm{C} 8$ ) and $\mathrm{O}-\mathrm{C}$ ( or O-C9') bonds of the tetrahydrofuran ring. As in the positive, also in the negative ion mode H/D exchange experiments allowed to confirm the nature of fragmentation products. In fact the ion at $m / z$ 151 does not contain deuterium atoms, confirming the mechanism that involves charge delocalization from the aromatic ring not containing the deuterium atom. In agreement with this hypothesis the CAD mass spectra of deprotonated medioresinol, syringaresinol and 3,4demethyleudesmin 4-O-glucoside, reported in literature (Eklud et al, 2008; Guo et al, 2007), 

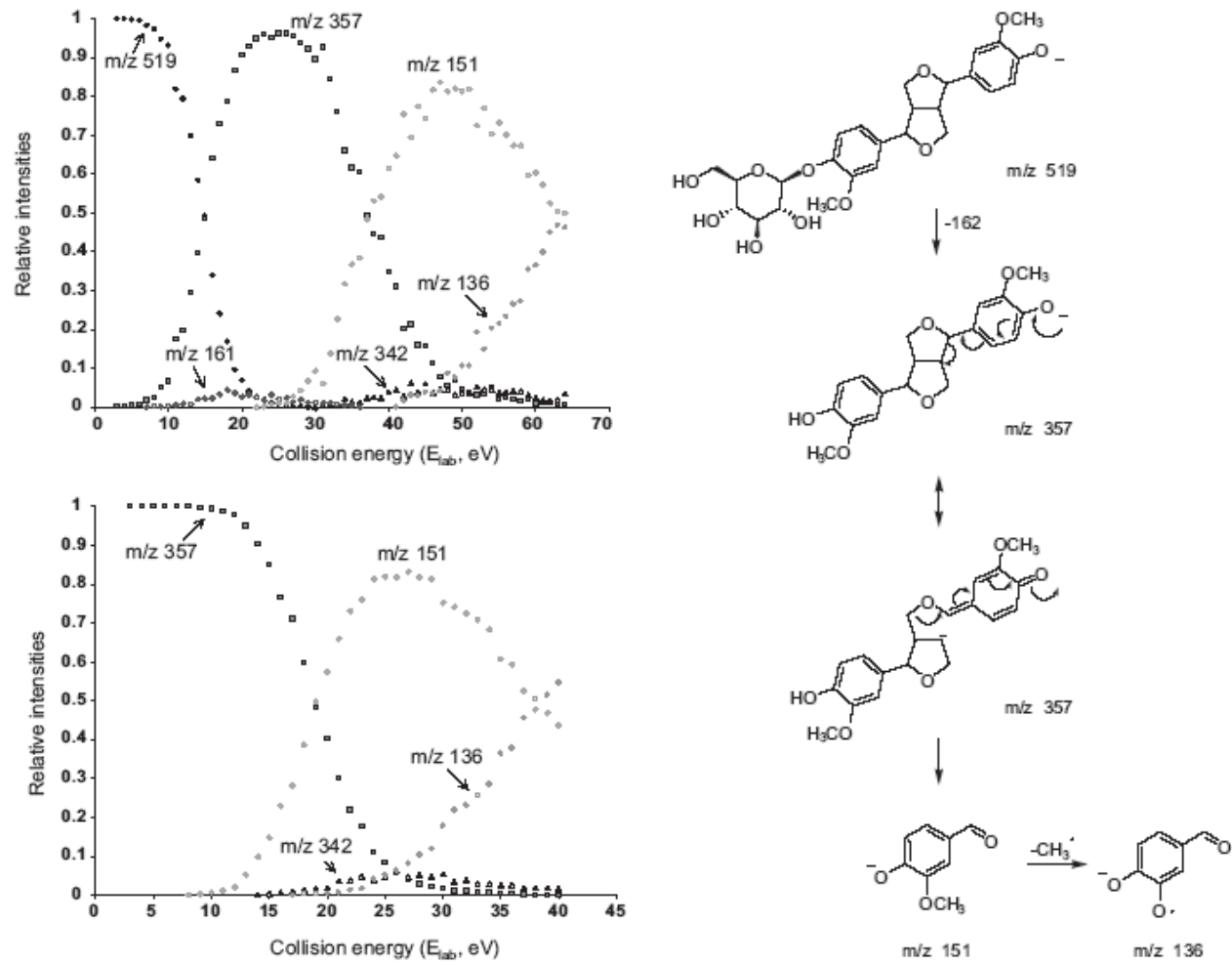

Fig. 8. Energy-resolved TQ/CAD mass spectrum of deprotonated pinoresinol 4-O- $\beta$-Dglucopyranoside (at $m / z 519$ ) and of deprotonated pinoresinol (at $m / z 357$ ) generated by insource CAD, and its hypothesized fragmentation mechanism.

exhibit syringyl $(\mathrm{m} / \mathrm{z} 181)$ and guaiacyl $(\mathrm{m} / \mathrm{z} 151)$ ions, or ions whose formation can be explained by this mechanism.

The presence in the $\mathrm{C}-8$ position of an $\mathrm{OH}$ substituent deeply modifies the fragmentation pathway. In fact likely it causes the $\mathrm{C}-\mathrm{O}$ bond cleavages in the furanic ring with the loss of $\mathrm{CH}_{2} \mathrm{O}$ units. It can be supposed that charge delocalization from the phenolic oxygen through the aromatic ring increases the electronic density charge at the C-7 carbon and the fragmentation pathways of furanic lignans reflect the effect of the $\mathrm{R}$ substituent in the C-8 position. So, if $\mathrm{R}=\mathrm{H}$, cleavage of the $\mathrm{C} 7^{\prime}-\mathrm{C} 8^{\prime}$ bond takes place, but when $\mathrm{R}=\mathrm{OH}$ the lower charge density in the C-8' position, due to the electron-withdrawing effect of this substituent, is assisted by charge delocalization from the ring through a hyperconjugative effect and the $\mathrm{C7}^{\prime}-\mathrm{C} 8^{\prime}$ bond gets stronger. Subsequently, $\mathrm{C} 7^{\prime}-\mathrm{O}$ bond cleavage occurs and leads to the loss of the $\mathrm{CH}_{2} \mathrm{O}$ unit (figure 9).

In order to get information on the collision-activated fragmentation mechanisms of THF lignans we first investigated the $[\mathrm{M}-\mathrm{H}]-\mathrm{CAD}$ fragmentation pattern of secoisolariciresinol (lignan 11), a lignan showing, instead of the tetrahydrofuran ring, a butanediol structure. Figure 10 shows the energy resolved CAD mass spectrum of deprotonated secoisolariciresinol at $m / z 361$. 


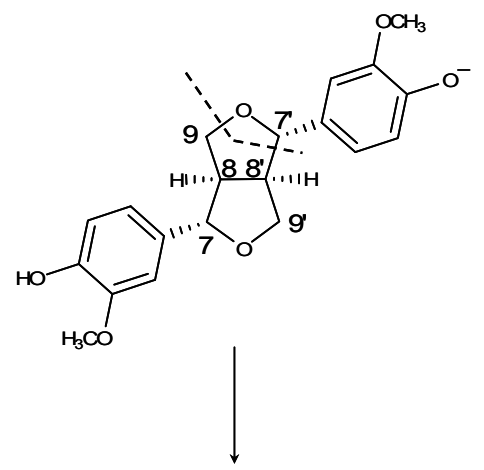

Formation of the ion at $\mathrm{m} / \mathrm{z} 151$<smiles>COc1ccc(C=O)cc1OC</smiles><smiles>COc1cc([C@@H]2O[C@H](c3ccc(O)c(OC)c3)[C@@]3(C)[C@@H](c4ccc(O)c(O)c4)OC[C@@]23C)ccc1[O-]</smiles>

Loss of $\mathrm{CH}_{2} \mathrm{O}$ units

Fig. 9. The effect of the R substituent in the C-8 position on the fragmentation mechanism.

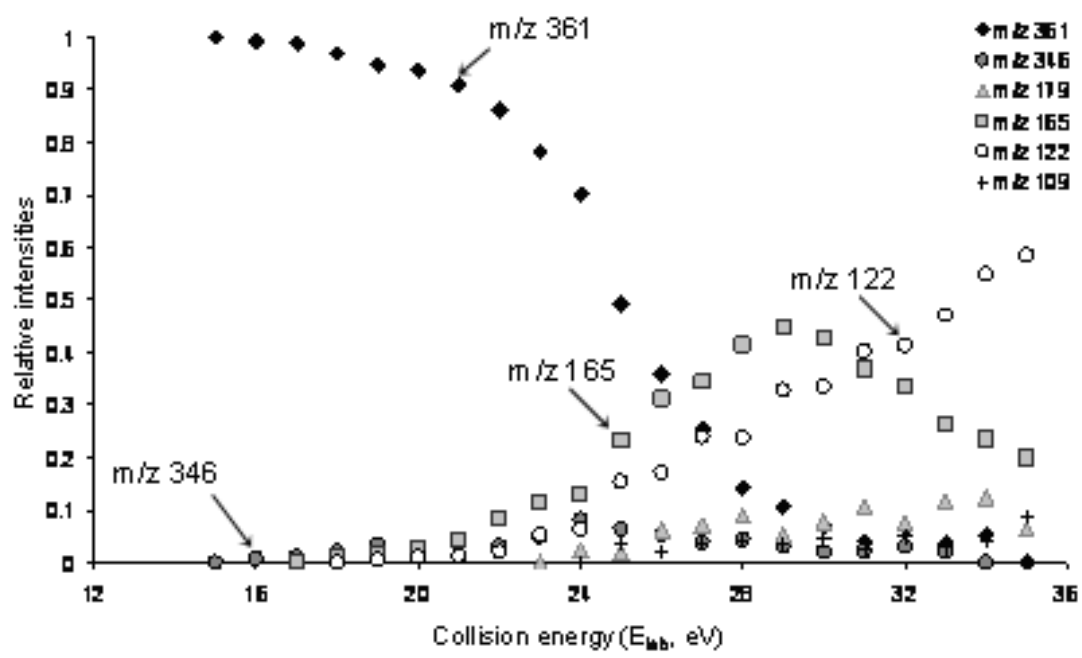

Fig. 10. [M-H]- energy resolved CAD mass spectrum of deprotonated secoisolariciresinol at $\mathrm{m} / \mathrm{z} 361$.

As previously reported (Eklund et al, 2008; Struijs et al, 2008) the loss of a methyl radical, occurring at relatively high collision energies $(<15 \mathrm{eV})$, leads to the formation of the ion at $m / z 346$ which, in turn, after $\beta$ - $\beta$ cleavage (C8-C $8^{\prime}$ bond) yields the ion at $m / z 165$ and at $m / z$ 179 , the main fragmentation channels together with the ion at $m / z 122$ at higher collision energies. The ion at $m / z 346$, generated by in-source CAD, is found to be the precursor ion of all these fragments. After H/D exchange experiments the $\mathrm{m} / \mathrm{z}$ ratio of the precursor ion 
shifts to $m / z 364$, according to the presence of three acidic hydrogen atoms and the ions at $\mathrm{m} / \mathrm{z}$ 346, 179 and 165 shift to $\mathrm{m} / \mathrm{z} 349,180$ and 166. On the basis of these evidences the possible fragmentation mechanism is reported in figure 11.

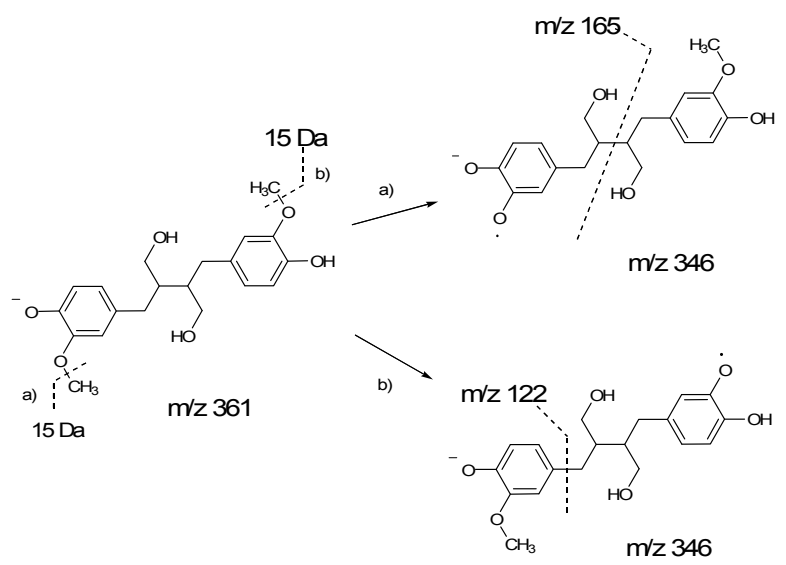

Fig. 11. The hypothesized fragmentation mechanism proposed for secoisolariciresinol.

According to figure 11, the CAD fragmentation pathway of secoisolariciresinol starts from the loss of a $\mathrm{CH}_{3}$ radical followed by the breaking of the $\beta-\beta\left(\mathrm{C} 8-\mathrm{C} 8^{\prime}\right)$ bond. It should be noted that only little intensities of the ion at $m / z 331$, deriving from the loss of $30 \mathrm{Da}\left(\mathrm{CH}_{2} \mathrm{O}\right)$, are observed (see later). To confirm our mechanistic hypothesis and to get further information, we considered the CAD fragmentation pattern, previously reported by Eklund and co-workers (Eklund et al, 2008), of deprotonated 7-hydroxysecoisolariciresinol (at $\mathrm{m} / \mathrm{z}$ 377) (figure 12).

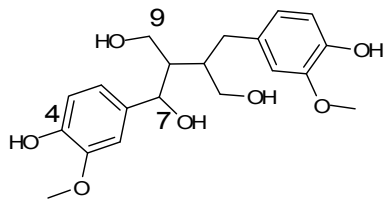

Fig. 12. The chemical structure of 7-hydroxysecoisolariciresinol.

For this lignan no loss of $\mathrm{CH}_{3}$. was observed, but a loss of $48 \mathrm{Da}$ takes place, which corresponds to the elimination of a water molecule (18 Da) and of a $\mathrm{CH}_{2} \mathrm{O}$ moiety (30 Da). We supposed that the loss of $\mathrm{CH}_{2} \mathrm{O}$ was not due to the initial deprotonation of the $\mathrm{C}(9) \mathrm{H}_{2} \mathrm{OH}$ group because it does not occur in secoisolariciresinol, but it involves a preliminary deprotonation at the $\mathrm{C}-4$ phenolic group and a charge delocalization through the aromatic ring. The occurrence of the $\mathrm{C}(7) \mathrm{OH}$ deprotonation can be considered, at least in principle, rather unlike by taking into account the high gas phase acidity difference between the phenolic and the secondary alcoholic positions. 
Thus, it can be concluded that in secoisolariciresinol the lack of oxidized benzylic positions compels an alternative fragmentation channel, namely the loss of a $\mathrm{CH}_{3}$ radical, which promotes the homolytic cleavage of the $\mathrm{C} 8-\mathrm{C} 8$ ' bond allowing the formation, during CAD processes, of stabilized radicals. Confirming this conclusion, the CAD fragmentation pattern of all the lignans having a butanediol structure reported by Eklund (Eklund et al, 2008) exhibit the same fragmentation pathways.

To investigate the fragmentation mechanisms of THF lignans, the [M-H]- CAD mass spectra of lariciresinol (lignan 5) and its $\mathrm{OH}$ derivatives (lignans 6-10) were compared in order to derive the influence of the $\mathrm{OH}$ group on the fragmentation mechanism, as explained for furofuranic lignans. The energy resolved CAD mass spectrum of deprotonated lariciresinol at $m / z 359$ (reported in figure 13) shows as the main fragmentation channel the loss of $30 \mathrm{Da}$, reasonably $\mathrm{CH}_{2} \mathrm{O}$, giving the ion at $m / z 329$ appearing at a collision energy threshold value $(\sim 4 \mathrm{eV})$ lower than that observed for the loss of the $\mathrm{CH}_{3}$. in secoisolariciresinol.

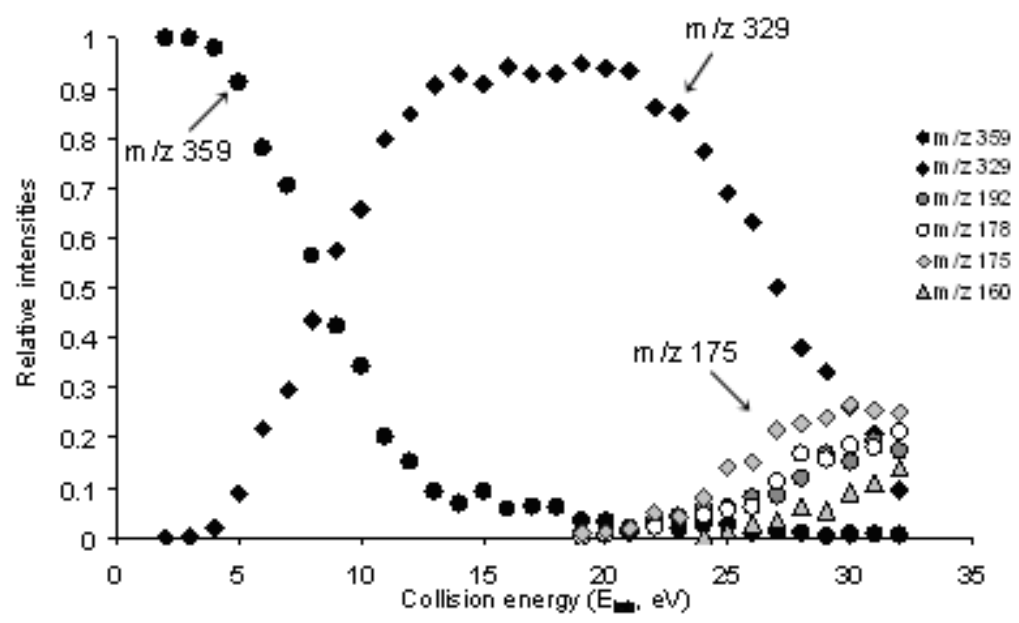

Fig. 13. Energy resolved CAD mass spectrum of deprotonated lariciresinol at $m / z 359$.

For each investigated THF lignan the loss of 30 Da occurs at low collision energies, except for compound $\mathbf{6}$ and $\mathbf{8}$, where it represents a minor fragmentation channel, and for secoisolariciresinol, where it is completely absent.

Therefore it is likely to hypothesize a generalized mechanism, namely the cleavage of the furanic ring and not of the $\mathrm{C}(9) \mathrm{H}_{2} \mathrm{O}$ chain. In confirmation, lignan 9, having a $3^{\prime}, 5^{\prime}$ dimethoxy, $4^{\prime}$-hydroxyphenyl instead of the guaiacyl moiety, showed the same fragmentation pattern of deprotonated lariciresinol. In fact, from deprotonated lignan $9 \mathrm{~m} / \mathrm{z}$ 389) after the loss of $30 \mathrm{Da}$ the ion at $\mathrm{m} / z 359$ is generated.

Finally, according to our mechanistic hypothesis on the basis of these experimental evidences and by considering the CAD mass spectra of deprotonated secoisolariciresinol we concluded that in lariciresinol and its derivatives the presence of the tetrahydrofuran ring instead of the butanediolic structure allows the breaking of the $\mathrm{C} 7-\mathrm{O}$ bond, due to charge delocalization from the oxygen bonded to the C-4 atom of the $A$ ring to the C-7 atom, leading to the loss of a formaldehyde molecule (figure 14). 

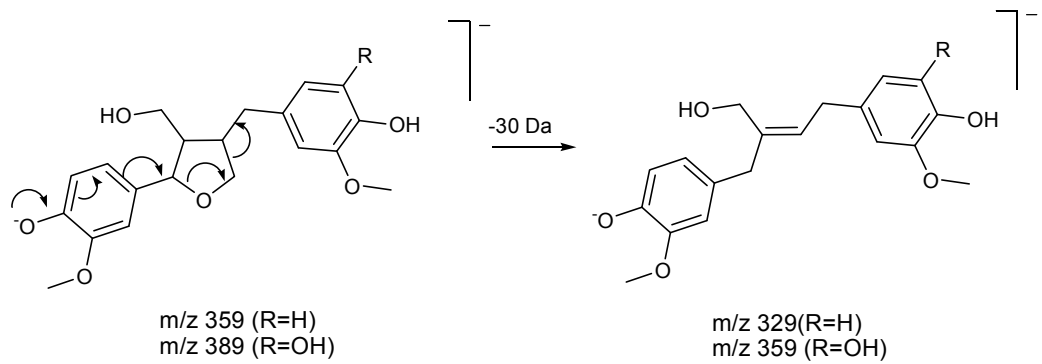

Fig. 14. Hypothesized mechanism for the loss of formaldehyde.

Lignan $\mathbf{1 0}$ is a lariciresinol derivative which differs for the presence of a hydroxyl substituent at the $\mathrm{C}-8$ position. Despite the presence of the $\mathrm{OH}$ group, also in this case a loss of $30 \mathrm{Da}\left(\mathrm{CH}_{2} \mathrm{O}\right)$ is observed at low collision energy values, comparable to those observed in lariciresinol for the same fragmentation. In figure 15 we report the energy resolved CAD mass spectrum of deprotonated lignan 10 at $\mathrm{m} / \mathrm{z} 375$.

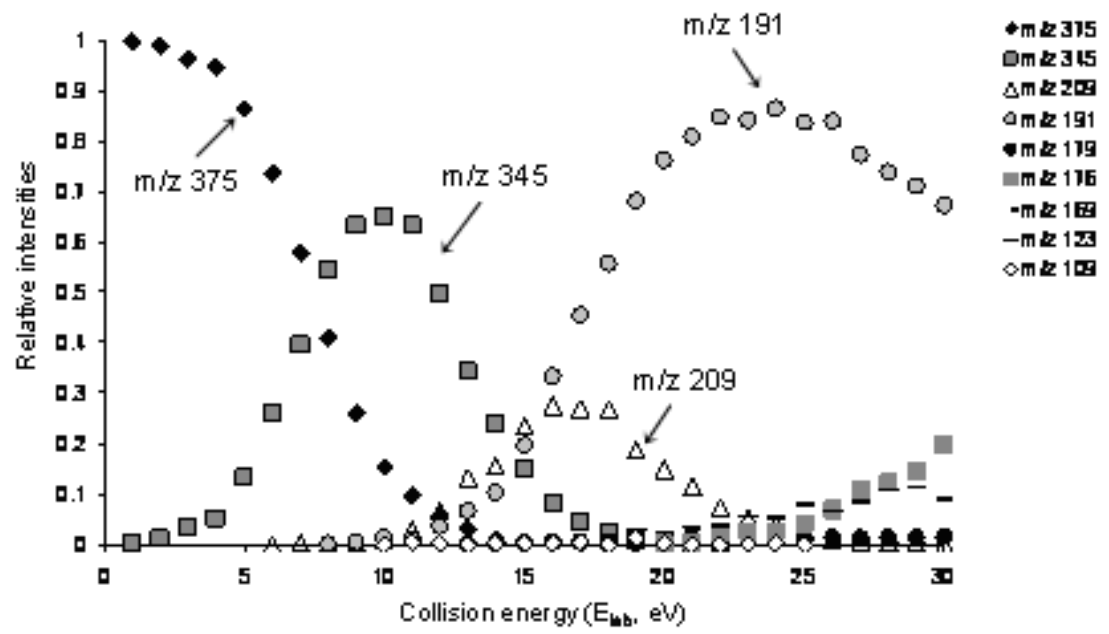

Fig. 15. Energy resolved CAD mass spectrum of deprotonated lignan 10 at $m / z 375$.

It seems to suggest that the presence of the $\mathrm{OH}$ substituent does not influence the mechanism for the loss of $30 \mathrm{Da}$. Therefore also in this case we hypothesized that the C7-O bond breaking takes place as a result of charge delocalization from the C-4 deprotonated position to the C-7 position and the cleavage of the $\mathrm{C} 8^{\prime}-\mathrm{C} 9^{\prime}$ bond leads to the loss of formaldehyde (figure 16). 


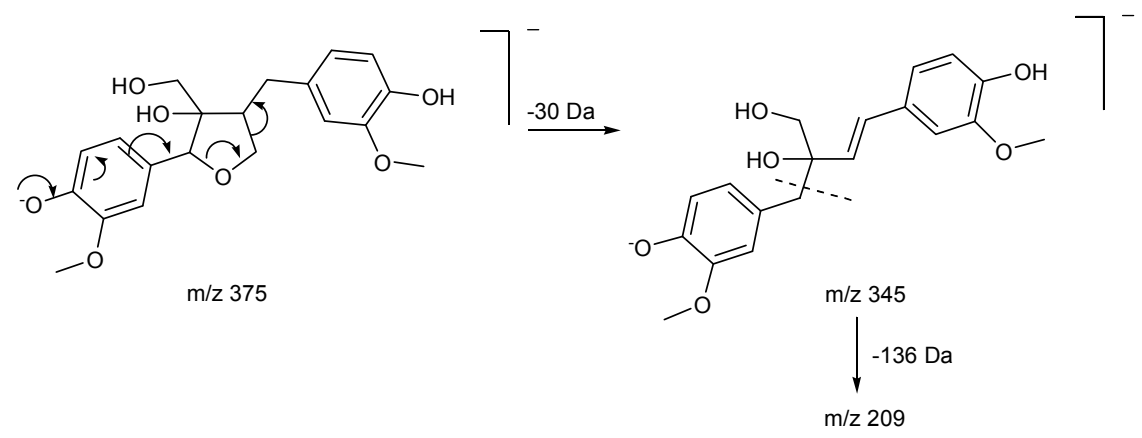

Fig. 16. Hypothesized fragmentation mechanism of deprotonated lignan 10.

The 7 '-hydroxylariciresinol, arising from lignan 7 after the loss of $162 \mathrm{Da}$, has an $\mathrm{OH}$ group bound at the C-7' position. The energy resolved CAD mass spectrum of deprotonated aglycone 7 at $\mathrm{m} / \mathrm{z} 375$ reported in figure 17 showed that both the fragment ions at $\mathrm{m} / \mathrm{z} 357$ ($18 \mathrm{Da})$ and $345(-30 \mathrm{Da})$, which structures are depicted in figure 18, are formed at comparable collision energies. In turn, these ions can lose $\mathrm{CH}_{2} \mathrm{O}$ and $\mathrm{H}_{2} \mathrm{O}$, respectively, giving the ion at $m / z$ 327. The latter ion can still lose $\mathrm{CH}_{2} \mathrm{O}$ yielding the fragment at $m / z 297$.

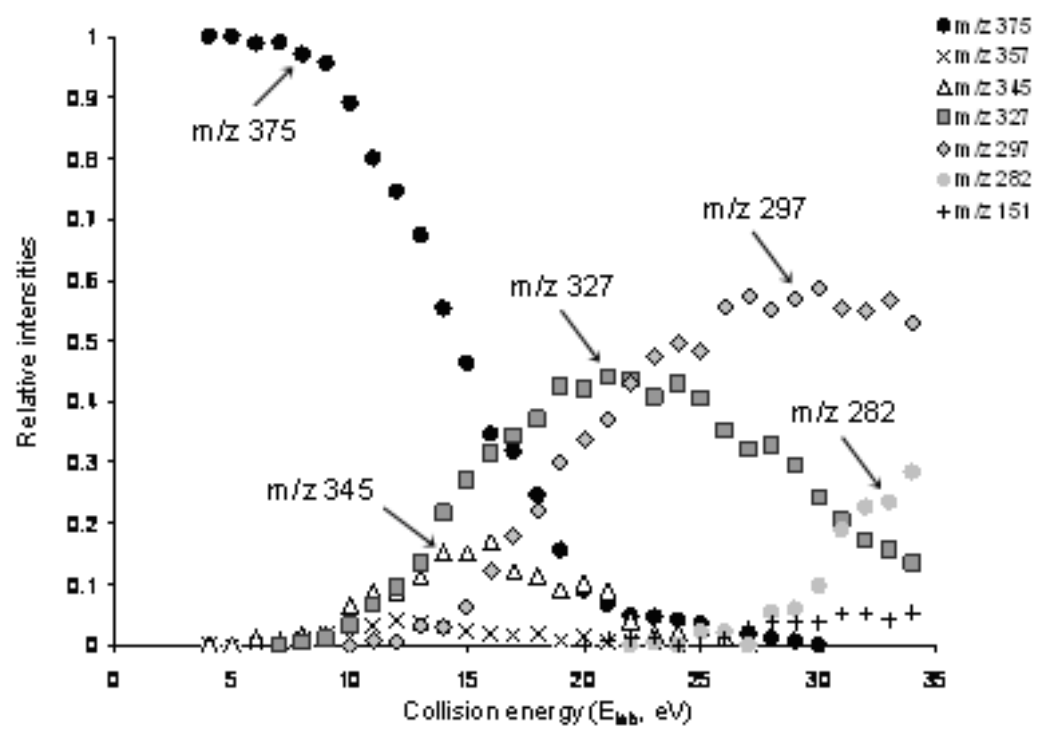

Fig. 17. Energy resolved CAD mass spectrum of deprotonated $7^{\prime}$-hydroxylariciresinol at $\mathrm{m} / \mathrm{z}$ 375.

In spite of the other THF lignans a charge delocalization from C-4' position (besides the delocalization from C-4 position) can be considered, and it is able likewise to justify the formation of the fragment ion at $m / z 327$ (figure 18). 
a)

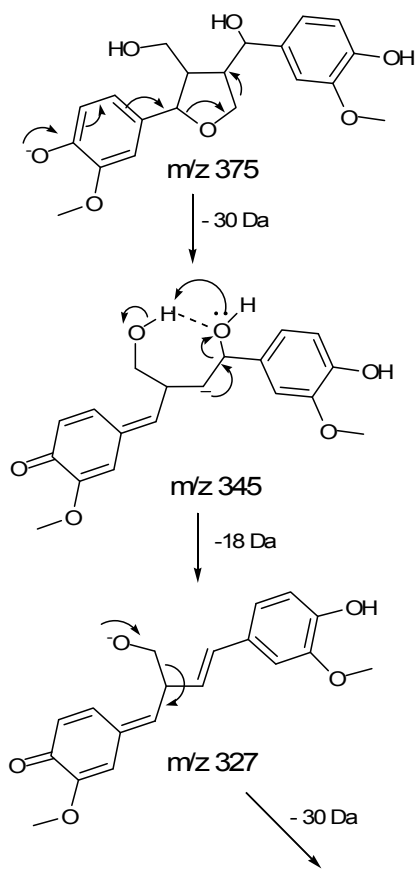

b)

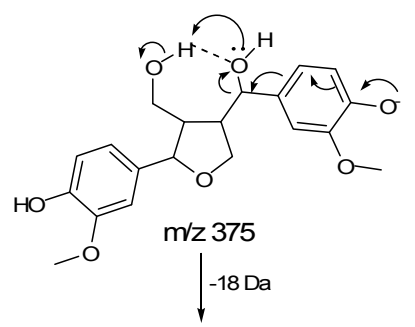<smiles>C=C/C=C\C=C1C(/C=C2\C=CC(=O)C(OC)=C2)COC1CO</smiles><smiles>COCCOCCOC</smiles>
$\downarrow-30 \mathrm{Da}$

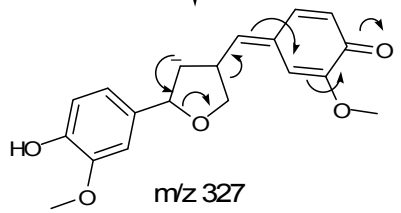<smiles>C=CC(=C)C=CC=Cc1ccc(O)c(OC)c1</smiles>

Fig. 18. Hypothesized fragmentation mechanisms for deprotonated 7'-hydroxylariciresinol.

Deprotonated aglycone ions from lignans 6 and 8 (figure 19) showed very similar fragmentation patterns. The energy resolved CAD mass spectrum reported in figure 19 refers to lignan aglycone 6 , but that of lignan aglycone 8 can be easily overlapped.

In both cases the spectrum seems to be deeply influenced by the presence of the $\mathrm{OH}$ group at the C-8' position. In fact it should be noted that only low intensities of the ion at $\mathrm{m} / \mathrm{z} 345$, arising from the loss of $\mathrm{CH}_{2} \mathrm{O}$, are present. We hypothesized that charge delocalization from the C-4 position causes the breaking of the $\mathrm{C} 7-\mathrm{O}$ bond but the loss of $\mathrm{CH}_{2} \mathrm{O}$ is prevented by a fast proton transfer from the tertiary $\mathrm{OH}$ alcoholic group at the $\mathrm{C}-8^{\prime}$ position to the $\mathrm{C}\left(9^{\prime}\right) \mathrm{H}_{2} \mathrm{O}$ chain (figure 20). 

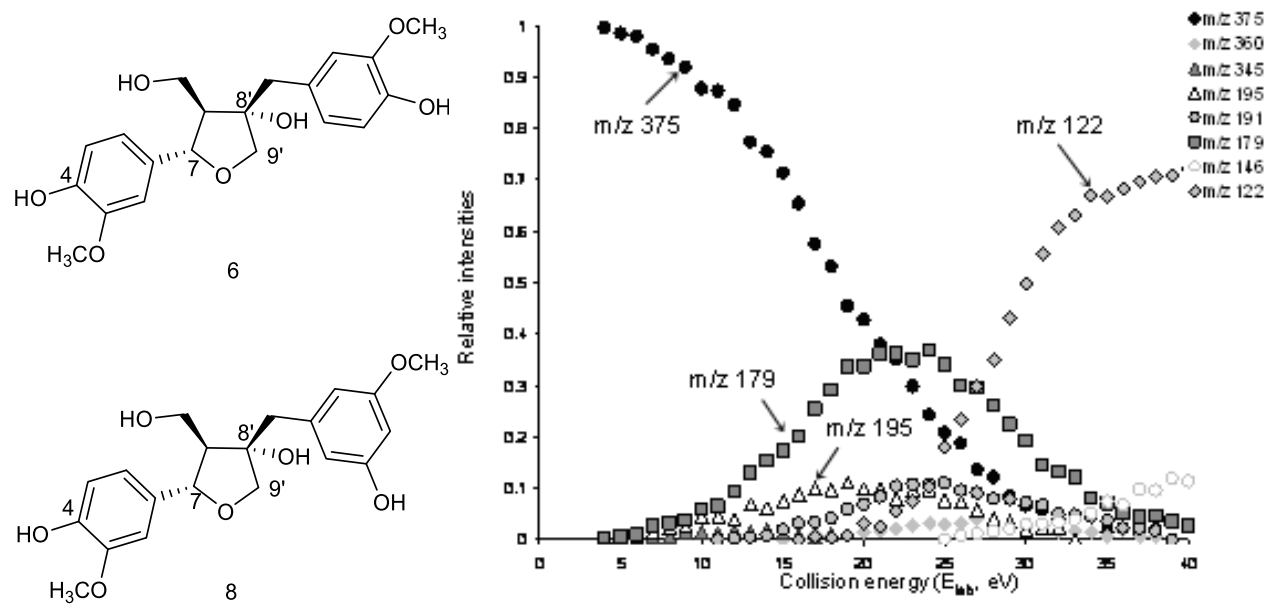

Fig. 19. Energy resolved CAD mass spectrum of deprotonated lignan 6 at $\mathrm{m} / \mathrm{z} 375$.

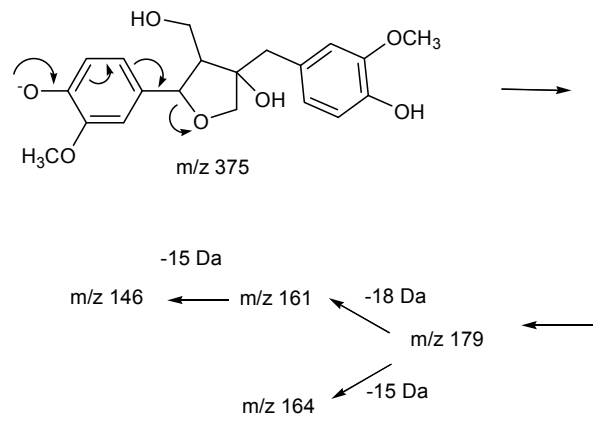<smiles>COc1cc(CC(O)(CO)C(C=O)CO)ccc1O</smiles><smiles>COC1=CC(=CC(=O)C(C)(CO)C(=O)Cc2ccc(O)c(OC)c2)C=CC1=O</smiles>

$\mathrm{m} / \mathrm{z} 375$

Fig. 20. Hypothesized fragmentation mechanism of deprotonated lignan 6.

\section{Tandem mass spectrometry and enzyme-mediated reactions: the Pinoresinol-Lariciresinol reductase}

Despite their importance for human health as well as for plant biology, systematic studies on the enzymes involved in the biosynthesis of lignans and isoflavonoids have only recently reported likely because only fairly recently have been identified several genes, proteins and enzymes involved in their biosynthetic pathways. Indeed, no NMR, and X- ray crystal structures up to now were available for structural analysis. The study of the biosynthetic pathways of monolignol derived dimers found as $8-5^{\prime}$, or $8-8^{\prime}$, or $8-\mathrm{O}-4^{\prime}$ linked moieties that, depending upon the specific plant species may be either optically active or racemic, leads to the isolation and characterization of various NADPH-dependent aromatic alcohol reductases, namely: i) pinoresinol-lariciresinol reductase (PLR) which catalyzes reduction of the 8-8' linked lignan, pinoresinol generating the secoisolariciresinol diglucoside in flaxseed (Linum usitatissimum) an important cancer preventive natural compound, as depicted in figure 21; ii) phenylcoumaran benzylic ether reductase (PCBER), and iii) isoflavone reductase (IFR), which 
are involved in central biosinthetic steps of various important bioactive lignans and isoflavonoids in a wide variety of plant species (Min et al, 2003).
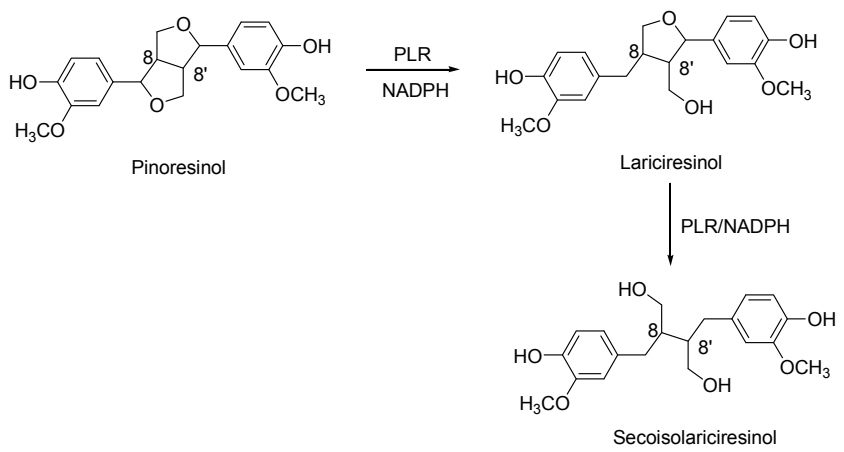

Fig. 21. Enzyme-mediated reduction from pinoresinol to secoisolariciresinol.

Interestingly, the enzyme reduction is obtained through the breaking of the $\mathrm{C} 7-\mathrm{O}$ bond, the same process occurring in the $\mathrm{CAD} / \mathrm{MS}$ experiments and leading as final step to the loss of the neutral fragment of $30 \mathrm{Da}, \mathrm{CH}_{2} \mathrm{O}$.

It can be envisaged that both the enzymatic and mass spectrometric processes could be favourite by the same factors and occur by a similar mechanism. In this context, gas phase ion chemistry evidences by tandem mass spectrometry of $[\mathrm{M}-\mathrm{H}]$-furanic lignan ions seems to attribute a key role to the negative charge delocalization from the oxygen atom at the $\mathrm{C}-4^{\prime}$ position of guaiacyl moiety to the C-7' position of tetrahydrofuranic ring, namely to the electron flux within the furanic ring.

Although very little is known about aromatic alcohol dehydrogenases, substrate modelling studies of the three related aromatic dehydrogenases PLR, PCBER, and IFR, carried out to predict both substrate binding and enzyme catalytic mechanisms suggest a [4R] -hydride transfer from the C-4 atom of the nicotinamide ring to the target bond of the corresponding substrate to be reduced, the nicotinamide ring resulting in a stacking mode to respect the aromatic ring which in turn is partially stabilized by stacking interactions and by additional interactions with residues within the active site. Here in particular there are conserved lysine residues which can be predicted to serve as the general base for catalysis. From a biochemical perspective, enzymatic reductions of PLR, IFR, and PCBER appear to be analogous and occur through formation and reduction of hypothetical enzyme-bound enone intermediates, in agreement with the hypothesized mechanism of CAD/MS fragmentation pathways.

\section{Conclusion}

The collisionally activated dissociation (CAD) mass spectra of $[\mathrm{M}-\mathrm{H}]^{-}$tetrahydrofuran and furofuran lignans, $\mathrm{M}=\mathrm{THF}$ and $\mathrm{M}=\mathrm{FUR}$, and of their alkali metal adducts [Alk+FUR] $]^{+}$ $[\mathrm{Alk}+\mathrm{THF}]^{+}$generated by electrospray ionization were investigated by Triple Quadrupole (TQ) mass spectrometry. The energy resolved TQ/CAD mass spectra were used in a qualitative way to infer information on the integrated energetic picture of CAD fragmentations and by means of a comparative approach, to get highlight into the mechanisms of the predominant dissociation/isomerization pathways of THF and FUR 
lignans. $\mathrm{H} / \mathrm{D}$ solution exchange experiments, performed by introducing the investigated compounds in $\mathrm{D}_{2} \mathrm{O} / \mathrm{CD}_{3} \mathrm{OD}$ solutions, allowed the selective $\mathrm{H} / \mathrm{D}$ exchange of all the more acidic hydrogen atoms and were employed to obtain information on the nature of fragments generated during TQ/CAD processes and on the mechanisms of the most important fragmentation pathways. The whole picture emerging from tandem mass spectrometric investigation on furofuran and tetrahydrofuran lignans allowed to infer generalized conclusion on the gas phase properties of their deprotonated ions to be extended to their enzymatic biosynthesis pathways.

\section{Acknowledgment}

The authors are grateful to the organic chemistry group of the Second University of Naples, to Prof. P. Monaco and A. Fiorentino, for the isolation and structural characterization by NMR spectroscopy of all the THF and FUR lignans, whose MS/MS spectra were reported in this manuscript. The authors are also grateful to Prof. F. Pepi of the University of Rome "Sapienza" for his QIT mass spectra.

\section{References}

Eklund, PC, Backman, MJ, Kronberg, LÅ, Smeds, AI, \& Sjöholm, RE. (2008). Identification of lignans by liquid chromatography-electrospray ionization ion-trap mass spectrometry. Journal of Mass Spectrometry, Vol.43, No.1, pp. 97-107

Guo, H, Liu, AH, Ye, M, Yang, M, \& Guo, D. (2007). Characterization of phenolic compounds in the fruits of Forsythia suspensa by high-performance liquid chromatography coupled with electrospray ionization tandem mass spectrometry. Rapid communications in Mass Spectrometry, Vol.21, No.5, pp. 715-729

Min, T, Kasahara, H, Bedgar, DL, Youn, B, Lawrence, PK, Gang, DR, Halls, SC, Park, H, Hilsenbeck, JL, Davin, LB, Lewis, NG, \& Kang, C. (2003). Crystal Structures of Pinoresinol-Lariciresinol and Phenylcoumaran Benzylic Ether Reductases and Their Relationship to Isoflavone Reductases. The journal of biological chemistry, Vol.278, No.12, pp. 50714-50723

Ricci, A, Fiorentino, A, Piccolella, S, Golino, A, Pepi, F, D’Abrosca, B, Letizia, M, \& Monaco, P. (2008). Furofuranic glycosylated lignans: a gas-phase ion chemistry investigation by tandem mass spectrometry. Rapid communications in Mass Spectrometry, Vol.22, No.21, pp. 3382-3392

Ricci, A, Fiorentino, A, Piccolella, S, D'Abrosca, B, Pacifico, S, \& Monaco, P. (2010). Structural discrimination of isomeric tetrahydrofuran lignan glucosides by tandem mass spectrometry. Rapid communications in Mass Spectrometry, Vol.24, No.7, pp. 979-985

Ricci, A, Piccolella, S, Fiorentino, A, Pepi, F, D’Abrosca, B, \& Monaco, P. (2010). A tandem mass spectrometric investigation of the low-energy collision-activated fragmentation of neo-clerodane diterpenes. Rapid communications in Mass Spectrometry, Vol.24, No.11, pp. 1543-1556

Struijs, K, Vincken, JP, \& Gruppen, H. (2008). Comparison of atmospheric pressure chemical ionization and electrospray ionization mass spectrometry for the detection of lignans from sesame seeds. Rapid communications in Mass Spectrometry, Vol.22, No.22, pp. 3615-3623 


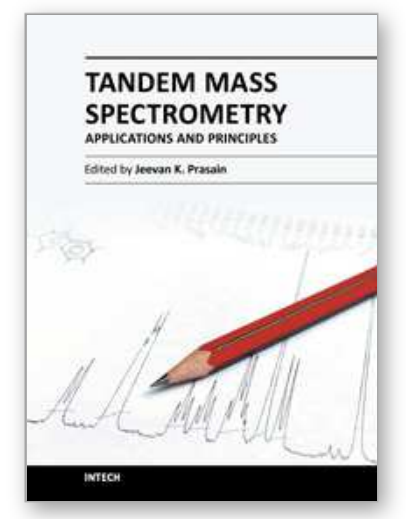

\author{
Tandem Mass Spectrometry - Applications and Principles \\ Edited by Dr Jeevan Prasain
}

ISBN 978-953-51-0141-3

Hard cover, 794 pages

Publisher InTech

Published online 29, February, 2012

Published in print edition February, 2012

Tandem Mass Spectrometry - Applications and Principles presents comprehensive coverage of theory, instrumentation and major applications of tandem mass spectrometry. The areas covered range from the analysis of drug metabolites, proteins and complex lipids to clinical diagnosis. This book serves multiple groups of audiences; professional (academic and industry), graduate students and general readers interested in the use of modern mass spectrometry in solving critical questions of chemical and biological sciences.

\title{
How to reference
}

In order to correctly reference this scholarly work, feel free to copy and paste the following:

Andreina Ricci and Simona Piccolella (2012). From the Collisionally Induced Dissociation to the EnzymeMediated Reactions: The Electron Flux Within the Lignan Furanic Ring, Tandem Mass Spectrometry Applications and Principles, Dr Jeevan Prasain (Ed.), ISBN: 978-953-51-0141-3, InTech, Available from: http://www.intechopen.com/books/tandem-mass-spectrometry-applications-and-principles/from-thecollisionally-induced-dissociation-to-the-enzyme-mediated-reactions-the-electron-flux-withi

\section{INTECH}

open science | open minds

\section{InTech Europe}

University Campus STeP Ri

Slavka Krautzeka 83/A

51000 Rijeka, Croatia

Phone: +385 (51) 770447

Fax: +385 (51) 686166

www.intechopen.com

\section{InTech China}

Unit 405, Office Block, Hotel Equatorial Shanghai

No.65, Yan An Road (West), Shanghai, 200040, China

中国上海市延安西路65号上海国际贵都大饭店办公楼 405 单元

Phone: +86-21-62489820

Fax: +86-21-62489821 
(C) 2012 The Author(s). Licensee IntechOpen. This is an open access article distributed under the terms of the Creative Commons Attribution 3.0 License, which permits unrestricted use, distribution, and reproduction in any medium, provided the original work is properly cited. 